УДК 316.442

DOI: 10.18101/1994-0866-2020-3-3-10

\title{
ИНТЕЛЛИГЕНЦИЯ РЕСПУБЛИК СИБИРИ В СОЦИАЛЬНОМ ПРОСТРАНСТВЕ
}

\section{(c) Осинский Иван Иосифович}

доктор философских наук, профессор, Бурятский государственный университет имени Доржи Банзарова Россия, 670000, г. Улан-Удэ, ул. Смолина, 24а intellige2007@rambler.ru

\section{(c) Добрынина Марина Ивановна}

доктор социологических наук, профессор, Бурятский государственный университет имени Доржи Банзарова Россия, 670000, г. Улан-Удэ, ул. Ранжурова, 6 mid16@mail.ru

Аннотация. В статье рассматриваются социальное положение интеллигенции в республиках Сибири, ее дифференциация (по отношению к средствам производства, уровню доходов, мировоззренческим ориентациям и др.), качество, обращается внимание на невысокий уровень жизни по сравнению с другими регионами России, нехватку благоустроенного жилья, относительно высокую заболеваемость. Серьезной проблемой является отток специалистов, особенно врачей, инженерно-технических и научных работников. Основными причинами оттока являются низкая заработная плата, безработица, узкий внутренний республиканский рынок с социально непрестижными рабочими местами, ограниченными возможностями для реализации молодыми специалистами своих профессиональных знаний. Нельзя не учитывать влияния этнического фактора - обострения в некоторых регионах межнациональных отношений. Отмечаются произошедшие сдвиги в мировоззренческих ориентациях интеллигенции, возросшее число интеллигентов, разделяющих религиозное мировоззрение, активизация деятельности интеллигенции по сохранению и развитию национальных языков, традиционных ценностей, усиление противодействия влиянию бездуховности, антигуманизма.

Ключевые слова: интеллигенция; республики; Сибирь; социальное пространство; социальная дифференциация; уровень жизни; мировоззрение; ценностные ориентации; культура; язык.

\section{Для цитирования}

Осинский И. И., Добрынина М. И. Интеллигенция республик Сибири в социальном пространстве // Вестник Бурятского государственного университета. Философия. 2020. Вып. 3. С. 3-10.

Сибирь - многонациональный регион, в котором проживают десятки этносов. Наиболее крупные из них имеют свои национально-государственные образования. Это Алтай, Бурятия, Тува, Хакасия, Якутия. В них проживает более 3 млн человек. За годы советской власти в каждой из них сформировались крупные группы многонациональной интеллигенции с весомой долей национальных специалистов. 
В постсоветский период произошли существенные трансформации их облика, стиля и образа жизни. Возросла численность специалистов с высшим и средним специальным образованием, особенно титульных наций, поднялся уровень национального самосознания, активизировалось осмысление проблемы национальной идентичности и др.

По инициативе и при ее активном участии их этносами были решены задачи национально-государственного самоопределения, выработки и реализации принципов взаимоотношения с Российским государством, определения отношения к историческому прошлому, традициям, верованиям, к проблемам национального языка, культуры и др. Многие из этих проблем актуальны и сегодня.

Цель данной статьи раскрыть некоторые актуальные проблемы социального пространства интеллигенции.

Общественное положение интеллигенции в социальной структуре общества, этноса определялось характером ее труда. Будучи связанной с интеллектуальным трудом и являя собой при социализме гомогенное образование, в постсоветское время интеллигенция автономий Сибири, как и страны в целом, оказалась расколотой, она распалась на различные группы: по отношению к средствам производства, по уровню доходов, по близости/отдаленности к власти, олигархическим группам, по ценностям, мировоззренческим ориентациям, отношению к глобализированному миру, по степени развитости этнонационального сознания и др. Анализ дифференциации российской интеллигенции постсоветского времени и классификация образовавших ее групп содержатся в работе А. И. Арнольдова, В. С. Семенова, Ж. Т. Тощенко. Мы, опираясь на эти и другие исследования, с учетом специфики дифференциации интеллигенции национальных районов Сибири попытались с определенной долей условности выделить 5 групп. Они приводились нами на XI Международной научной конференции «Российская интеллигенция, ее гражданские позиции в современном обществе» 16 июня 2016 г. В данной статье мы их только назовем.

Первая группа - управленцы, если они отвечают общепризнанным духовнонравственным критериям, их составляют высокопоставленные чиновники, руководители крупных производственных объединений, некоторые представители научной и вузовской интеллигенции. Ядро этой группы - представители законодательной, исполнительной, судебной власти, региональных политических элит, руководители политических партий. Они характеризуются высоким уровнем доходов, являются наиболее активной и влиятельной частью в системе управления.

Вторая группа - специалисты в области политических услуг, идеологи власти и олигархической верхушки, некоторые ученые, прежде всего из числа обществоведов, многие журналисты, телекомментаторы, работники СМИ. Это политическая и идеологическая опора власти и олигархата.

Третья группа - специалисты, знающие и добросовестно выполняющие свои функциональные обязанности. К власти относятся индифферентно. Не участвуют в деятельности политических партий. Положительно относятся к прежнему строю, его ценностям. 
Четвертая группа - духовенство. Члены этой группы выполняют мировоззренческую, компенсаторную, культурную и другие функции. Все больше выступают опорой власти. Могли бы более активно влиять на социальные преобразования, улучшение духовно - нравственной атмосферы в обществе.

Пятая группа - самая многочисленная. Это народная интеллигенция. К ней относятся многие ученые, работники культуры, ИТР, учителя, врачи и многие другие, которые по социальному, духовному, нравственному складу являются неотрывной частью народа.

Одной из особенностей дифференциации интеллигенции ряда национальных районов Сибири является группировка части интеллигенции по признакам клановой принадлежности. Она, естественно, не афишируется. Порочность данной дифференциации в том, что представители того или иного клана попадают на престижные должности не по профессиональным, деловым качествам, а по родственным, сохранившимся племенным признакам. Эта практика получила свое распространение среди интеллигенции в сфере управления, в вузовской, научной средах. Проблема клановости, ее пагубность, формы проанализированы в монографии Чимзы Кудер-ооловны Ламажаа «Клановость в политике регионов России. Тувинские правители» [6].

Характеризуя современную интеллигенцию, нельзя не обратить внимание на снижение ее качества как в Сибири, так и в стране в целом, что, по мнению исследователей, связано с ухудшением общеобразовательной (в школе), профессиональной (в вузе) подготовки молодежи, а также с утратой все большей ее частью качеств интеллигентности. В литературе это ухудшение во многом связывается с болонским процессом. Так, по данным Центра научно-политической мысли и идеологии (сентябрь 2015 г.), качество образования после присоединения к Болонскому процессу стало существенно хуже. Профессор Якутского госуниверситета Н. В. Бекетов пишет: «Сегодня уровень профессионального и высшего образования в России не просто снизился, но упал до критически низкой отметки. Когда в целых отраслях уже не осталось квалифицированных кадров. Либо их потребность удовлетворена (как, например, в обслуживании ЭВМ) не более чем на 50\% [1, c. 787-804]. На качестве подготовки специалистов сказывается слабое финансирование вузов, особенно периферийных, что не позволяет им развивать материально-техническую, научную, учебную базу, привлекать высококвалифицированных специалистов, в том числе зарубежных университетов, направлять преподавателей на научные конференции, развивать студенческую науку.

Интеллигенция национальных районов Сибири в массе своей характеризуется невысоким качеством жизни. Оно заметно ниже, чем в других регионах России. Это особенно видно на величине зарплат наиболее массовых отрядов интеллигенции, какими являются учителя, медицинские, культурно-просветительные работники.

Согласно данным Росстата за 2019 г., среднемесячная заработная плата учителя в Москве составила 97,2 тыс. р., в Бурятии - 34,3 тыс. Примерно такой уровень оплаты труда учителей и в других регионах Сибири, где в среднем по СФО в 2018 г. она составляла 34,4 тыс. р. В целом по стране зарплата учителя составляет 40,4 тыс. p. Это в 2,5 раза меньше минимальной зарплаты в Англии и во Франции, где она равняется более 100 тыс. р. 
Социологической лабораторией Бурятского госуниверситета совместно с социологами Тувы периодически проводятся опросы интеллигенции Тувы. Последний (четвертый) был проведен в 2017 г. Опрошено 499 человек.

Таблица 1

На вопрос «Испытываете ли Вы материальные затруднения?» были получены следующие ответы

\begin{tabular}{|c|l|c|c|}
\hline & \multicolumn{1}{|c|}{} & $\begin{array}{c}\text { число ре- } \\
\text { спондентов }\end{array}$ & \% \\
\hline 1 & Денег не хватает даже на питание & 8 & 1,6 \\
\hline 2 & Денег хватает только на питание & 60 & 12,0 \\
\hline 3 & $\begin{array}{l}\text { На питание и одежду денег хватает, но на более крупные } \\
\text { покупки приходится откладывать на потом }\end{array}$ & 248 & 49,7 \\
\hline 4 & $\begin{array}{l}\text { Денег вполне хватает на покупку бытовой техники, но мы } \\
\text { не можем купить автомобиль, дачу }\end{array}$ & 89 & 17,8 \\
\hline 5 & $\begin{array}{l}\text { Денег хватает на все, кроме таких дорогих приобретений, } \\
\text { как квартира и дом }\end{array}$ & 54 & 10,8 \\
\hline 6 & $\begin{array}{l}\text { Мы можем позволить себе купить машину, дачу, словом, } \\
\text { ни в чем себе не отказывать }\end{array}$ & 8 & 6,4 \\
\hline 7 & Затрудняюсь ответить & 32 & 100,0 \\
\hline & Всего & 499 & \\
\hline
\end{tabular}

Опираясь на самооценку респондентов, исследователи выделили в составе интеллигенции три класса: высший класс - 1,6\%, средний $-28,6 \%$ и базисный (бедный) - 63,3\%.

Несколько лучше обстоит дело с оплатой труда другой массовой профессии - врачей. Согласно данным Росстата, среднемесячная зарплата врачей в России за 2016 г. составила 50,7 тыс. р. (в декабре министр здравоохранения РФ В. С. Скворцова назвала цифру 53 тыс. р.). В Сибирском федеральном округе 41,75 тыс. р., в Москве - 70 тыс. p. Во многих регионах - 27,4 тыс. р., и то с учетом повышения окладов на $25 \%$ от первоначального.

В последние годы зарплата врачей заметно возросла. Если верить статистике, в 2018 г. среднемесячная зарплата у российских врачей поднялась до 74 тыс. руб., у сибирских — до 65,7 тыс., у врачей Республики Алтай — до 48,4 тыс., у московских (городских) - до 137,5 тыс. p.

Серьезной проблемой интеллигенции, особенно сельской, является потребность в благоустроенном жилье. В автономиях Сибири низкий уровень урбанизации. В половине из них более $40 \%$ населения, включая, разумеется, интеллигенцию, - это сельские жители, а в Республике Алтай они составляют более 70\%, где практически отсутствует благоустроенное жилье. В целом же в республиках Алтай, Бурятия, Тува, включая городское население, уровень благоустроенности не превышает 40\%. Например, в Бурятии в сельской местности в 2018 г. (конец года) были оборудованы водопроводом $13 \%$ жилья, отоплением - $13 \%$, канали- 
зацией $-11 \%$, газом $-22 \%$, ваннами (душем) $-9 \%$, горячим водоснабжением - 7\% ${ }^{1}$. По данным Росстата, в СФО в целом показатели благоустроенного жилищного фонда на $10-15 \%$ ниже российского усредненного показателя.

От уровня благоустроенности жилья зависит не только объем свободного времени, его использование, но в условиях Сибири - здоровье человека. По данным Комитета экспертов ВОЗ, на долю природно-климатических факторов приходится 20-24\% всей совокупности формирующих общественное здоровье обстоятельств. Рассматриваемые нами регионы, как и Сибирь в целом, находятся в географической зоне резко континентального климата (температуры зимой и летом от 50 градусов мороза до 50 градусов жары), что не может бесследно проходить для человеческого организма. Не случайно в этих районах значительно выше уровень заболеваний и смертности, особенно сельского населения (смертность на $20 \%$ выше, чем в городе). Они хуже обеспечены врачами. В 2019 г. в Бурятии не хватало более 600 врачей и 720 человек среднего медперсонала. По сравнению с девяностыми годами количество медицинских работников в этих районах увеличилось. Положительную роль сыграла программа «Земский доктор». Согласно которой в Бурятии с 2011 по 2017 г. были направлены в сельские районы республики 769 врачей с получением единовременной выплаты в размере 1 млн рублей. Из числа направленных в 2011-2012 гг. по истечении обязательных 5 лет большинство вернулось в Улан-Удэ. В качестве причины выезда из сельской местности они при анкетировании указали отсутствие жилья, неразвитость инфраструктуры на местах, отсутствие условий для дополнительного образования детей.

Проблематичным является обеспечение этих регионов учителями. На 14 сентября 2019 г., по словам министра образования и науки Республики Бурятия, в сельских школах было открыто 637 вакансий. Не хватало учителей начальных классов, преподавателей иностранных языков, математики, русского языка и литературы.

Серьезной проблемой автономий, как и Сибири в целом, является отток из этих районов населения, особенно специалистов - врачей, инженеров, научных работников и др. Причем с каждым годом число уезжающих увеличивается. В 2018 г. из Сибири уехало в 1,5 раза больше, чем в 2017 г. В Бурятию прибыло 13,3 тыс., а уехало около 18 тыс., т. е. на 4,6 тыс. больше. Убыль в Туве составила 980 чел., в Хакасии - 900 чел. В Якутии только за первые два месяца 2018 г. потери составили 974 чел. [2, с. 60]. 3/4 уезжающих, по данным социологов, - специалисты.

По оценкам экспертов, около 60\% молодежи, получившей высшее образование в других городах, не возвращаются на свою историческую родину (в Бурятию) $[4$, с. 350]. Основные причины миграции специалистов кроются в особенностях социально-экономического развития регионов: низкая зарплата, безработица, узкий внутренний республиканский рынок с низкооплачиваемыми вакансиями и социально непрестижными рабочими местами, ограниченными возможностями для реализации молодых специалистов. Многие из них теряют перспективу осуществить свои планы, намерения в Сибири. Выезжают в основном в Москву, Московскую область, Санкт-Петербург, на юг России. Некоторые - за рубеж. Часть

\footnotetext{
${ }^{1}$ Бурятия - 2019. Стат. ежегодник № 01-01-12. Улан-Удэ, 2019. С. 133.
} 
в другие регионы. Нельзя не учитывать и этнический фактор миграции. Так, в потоке выезжающих из Бурятии в другие регионы страны преобладали русские, в потоке въезжающих в республику - буряты. За период с 1989 по 2010 г. число русских в Бурятии уменьшилось на 95,4 тыс. человек. Бурятское население, напротив, увеличилось за эти годы на 37,3 тыс. ${ }^{1}$ Рост произошел за счет более высокой рождаемости и миграции из других регионов России, в основном из сопредельных. Отток населения из Бурятии, как уже отмечалось, продолжался и в последующие годы. В нем участвуют и специалисты бурятской национальности.

В 1990 г. в связи с резко обострившимися межнациональными отношениями в Туве 12,3 тыс. человек выехало за пределы республики ${ }^{2}$, львиную долю составили специалисты - ИТР, врачи, агрономы, управленцы. В результате многие заводы и учреждения остановились. Ситуация, возникшая в Туве, свидетельствует о том, что межнациональные отношения играют весьма существенную роль в миграционных процессах, могут служить причиной оттока части населения, в том числе специалистов.

Анализ тенденций последних лет и намерений специалистов указывает на то, что отток специалистов из Сибири продолжается. В 2018 г. были проведены социологические исследования среди студенческой молодежи Забайкалья. Результаты были размещены в интернете. $74,2 \%$ студентов в своих ответах выразили желание после окончания учебы уехать из Забайкалья. Основными причинами желания покинуть регион были указаны: дороговизна жизни $(55,5 \%)$, низкий уровень зарплат, стипендий, пособий $(67,7 \%)$, высокие цены на товары и услуги $(62,6 \%)$, низкий уровень социально-экономического развития $(44,7 \%)^{3}$. Значительная часть специалистов реализует свои намерения. В 2018 г. прибыло в Забайкалье 29,3 тыс. человек, а выбыло 36,7 тыс. Многие специалисты работают не по специальности, полученной в вузе. По данным исследования РАНХ и ГС, только у $37 \%$ профессия соответствует диплому [3]. Одна из основных причин - отсутствие работы по данной специальности.

Произошли изменения в мировоззренческих ориентациях интеллигенции. Вместо утверждавшегося в прошлом единого у всех материалистического мировоззрения в настоящее время в национальных районах Сибири значительное влияние получило религиозное мировоззрение. Так, с 1995 по 2011 г. в Бурятии число верующих среди представителей русской интеллигенции увеличилось в 1,7 раза и составило 50,5\%, среди бурятской - в 1,6 раза и составило 61,6\%. В Туве в 2013 г. действовало 53 религиозных объединения, в том числе 23 буддийской направленности, 11 - русской православной церкви, 1 - старообрядческая, 11 - проте-

\footnotetext{
${ }^{1}$ Бурятия в цифрах (Краткий стат. сборник № 02-3). Улан-Удэ, 1999. С. 18.

2 Численность естественного движения населения и миграция населения Республики Тыва // Текущий архив отдела переписей населения Госкомстата Республики Тыва за 1995 г. С. 23.

${ }^{3}$ Высшее образование в Забайкальском крае. URL: https://infourok.ru/vissheeobrazovanie-v-zabaykaskom-krae-problemi-i-puti-ih-resheniya-276098.8html (дата обращения: 23.03.2019).
} 
стантской направленности, 8 - шаманистские организации. Повсеместно при активном участии интеллигенции широкое развитие получило строительство храмов, проведение массовых религиозных мероприятий, в школах был введен предмет «Основы религиозной этики и культуры» [5, с. 4, 11].

Интеллигенция рассматриваемых регионов большое внимание уделяет проблемам сохранения и развития национальных языков, культуры, традиционных духовно-нравственных ценностей. Одновременно противостоит влиянию бездуховности, антигуманизма, внедряющихся в сознание людей через СМИ.

В заключение следует отметить, что интеллигенция в автономиях Сибири в постсоветское время выросла численно, произошли некоторые позитивные изменения в ее структуре. В то же время она социально расколота. Основная ее часть характеризуется низким жизненным уровнем, трудностями в выполнении своих функциональных обязанностей, увеличивающимся оттоком в другие регионы страны. Наблюдается падение качества интеллигенции. Проблемы, названные в статье, требуют принятия органами власти неотложных мер по кардинальному улучшению социально-экономического развития национальных районов Сибири, повышению уровня и качества жизни населения, охране здоровья, прекращению ее оттока в другие регионы. Требуется выработка и реализация системы мер по комплексному развитию Сибири и Дальнего Востока с учетом специфики природно-климатических условий данных регионов.

\section{Лuтература}

1. Бекетов Н. В. Основные приоритеты формирования государственной демографической политики России // Национальная идентичность России и демографический кризис: материалы всерос. науч. конф. (Казань, 13-14 ноября 2008 г.). М., 2009. С. 787-804.

2. Бреславский А. С. Урбанизация в республиках Южной Сибири: динамика ключевых параметров (1989-2019) // Урбанистика. 2019. № 1. C. 58-67. DOI: 10.7256/2310 8673.2019.1.29217 URL: https://nbpublish.com/library_read_article.php?id=2921 (дата обращения: 20.01.2020).

3. Ивойлова И. Образован и не нужен. URL: https://rg.ru/2018/06/04/tolko-37procentov-vypusknikov-rabotaiut-po-specialnosti.html (дата обращения: 04.02.2020).

4. Тартыгашева Г. В. Интеллигенция и региональные культурные пространства // «Новая» и «старая» интеллигенция: общее и особенное: сб. ст. / под ред. Ж. Т. Тощенко. M., 2012. C. 350.

5. Хомушку О. М. Возрождение духовности в Туве: от прошлого к настоящему // Единая Тува в Единой России: история и современность, перспективы: материалы междунар. науч. конф. Абакан, 2014. С. 4,11.

6. Ламажаа Ч. К. Клановость в политике регионов России. Тувинские правители. СПб.: Алетейа, 2010. 208 с.

Статья поступила в редакиию 21.09.2020; одобрена после рещензирования 25.09.2020; принята к публикаџии 28.09.2020. 
INTELLIGENTSIA OF THE SIBERIAN REPUBLICS IN THE SOCIAL SPACE

Ivan I. Osinsky

Dr. Sci. (Philos.), Prof.,

Dorzhi Banzarov Buryat State University

24a Smolina St., Ulan-Ude 670000, Russia

intellige2007@rambler.ru

Marina I. Dobrynina

Dr. Sci. (Sociol.), Prof.,

Dorzhi Banzarov Buryat State University

6 Ranzhurova St., Ulan-Ude 670000, Russia

mid16@mail.ru

Abstract. The article discusses the social status of the intelligentsia in the republics of Siberia, its differentiation in terms of the means of production, income level, and worldview, we draw attention to the low standard of living, lack of comfortable housing, higher morbidity in Siberia in comparison to other regions of Russia. A severe problem is the outflow of specialists, especially physicians, engineers, and scientists. The main reasons for the outflow are low wages, unemployment, narrow labour market offering lowly occupations, limited opportunities for young specialists in implementation of their professional knowledge. We cannot but take into account the influence of the ethnic factor, which is manifested in the aggravation of ethnic tension in some regions. The article emphasizes the changes that have taken place in the ideological orientations of the intelligentsia, the increased number of intellectuals who share a religious worldview. There has been observed the increase in the activity of the intelligentsia on preservation and development of national languages, traditional values , and the counteraction to the influence of earthliness and antihumanism.

Keywords: the intelligentsia; republics; Siberia; social space; social differentiation; standard of living; worldview; value orientations; culture; language. 